cattle and the Welsh Tourist Board, on its brochures, should advertise this fact very clearly, explaining at the same time how to prevent human disease. It is commonly believed that milk in bottles is invariably pasteurized, that milk served in all large hotels (and universities) is pasteurized, and that milk supplied by licensed producer/ retailers in bottles labelled "untreated" must be brucella-free. But these are misconceptions, ${ }^{1}$ and holiday makers should be encouraged to demand milk which has been properly pasteurized or, alternatively, to boil it if, bravely, they are prepared to accept it raw.

Farmers, especially those who are themselves licensed producer/retailers, claim that there is no risk in drinking milk from accredited brucella-free herds, and the college herd at Aberystwyth is in this category. Infection, however, can be re-introduced into a clean herd, especially when it is present on neighbouring farms, and because of the interval between tests evidence of breakdown may be found only in retrospect. Furthermore, cows infected late in pregnancy, while they excrete brucella organisms, may at first show no clinical or immunological evidence of disease and may give birth to healthy calves.

Government, judging from its record, does not fear the risk from brucellosis to holiday makers, visitors from abroad, and members of the B.M.A., who are all tourists in rural Britain, provided that the industry thrives. Informed tourists would be better able to protect themselves, and a penitent B.M.A., through the medium of its lay publications, should seize this opportunity to atone.-I am, etc.,

EIRIAN WILLIAMS

Pembroke County War Memorial Hospital, Haverfordwest

1 Williams, E., Lancet, 1970, 1, 1220.

\section{Ketamine Anaesthesia}

SIR,-The finding of depression of laryngeal reflexes during ketamine anaesthesia by Drs. P. A. Taylor and R. M. Towey (19 June, p. 688) is of great importance, particularly in view of a description by workers from this department of its use as sole agent in obstetrics. ${ }^{1}$

We were aware of this possibility and have carried out a similar investigation in 20 patients. These were undergoing postpartum tubal ligation under intermittent ketamine following either atropine or no premedication. The medium was injected once anaesthesia had been stabilized, but to reduce exposure to radiation a single $x$-ray was taken at the end of the operation-for example, 40-60 minutes later. In only one of our patients was there evidence of aspiration, although on occasions the outline of the oesophagus was seen in the radiograph. The patient in whom there was evidence of tracheal contamination received a very large $(850 \mathrm{mg})$ dose of ketamine and also $10 \mathrm{mg}$ diazepam.

One would like to know the dose of ketamine given by Drs. Taylor and Towey for, as pointed out in your leading article (p. 666), sedatives and all general anaesthetics reduce activity of laryngeal reflexes. Our patients were very light during surgery and able to swallow and phonate and this may account for the discrepancy of findings. In continuing studies a few observations made using an image intensifier tend to support this. The use of hyoscine as premedication may also have played a part as this has a strong hypnotic action.

We have stressed $^{1}$ that the safety of ketamine in the presence of a full stomach is not known. Drs. Taylor and Towey have shown that it is certainly unsafe under certain circumstances, but this could be owing to the use of unnecessarily large doses such as could easily occur from continuous infusion. With ketamine, more than with any other anaesthetic, slight movement of the patient (particularly after hyoscine) could be interpreted as light anaesthesia. We hope to present our full findings in the near future.We are, etc.,

\section{JOHN W. DUNDEE} JAMES MOORE

Department of Anaesthetics

The Queen's University of Belfast,

Northern Ireland 1 Bovill, J. G., Coppel, D. L., Dundee, J. W., and
Moore, J., Lancet, 1971, 1, 1285.

SIR,-I am a little worried by the letter from Lieutenant-Colonel T. R. Austin and Captain D. R. Bevan regarding paralysis with succinylcholine as a means of obtaining a still patient under ketamine anaesthesia. On more than one occasion I have found a still ketamine patient give a convulsive jerk and become restless at the application of a knife, as evidence of insufficient analgesia. One feels the need to emphasize testing the degree of analgesia before paralysing the patient. - I am, etc.,

R. LUNT

Littleover,

Derby

SIR,-Two days after reading the articles and letter dealing with ketamine (19 June, pp. 666,688 , and 709), I had the following experience while using the drug.

A $10 \mathrm{~kg}$ one-and-half-year-old female child who was to have a plaster spica applied for a congenital dislocation of hip was given $125 \mathrm{mg}$ ketamine intramuscularly. She had been premedicated with oral trimeprazine (Vallergan Forte) two-and-half hours previously but was only lightly sedated. Five minutes later the child was unconscious and developed respiratory obstruction and cyanosis caused by thick salivary secretions. She was able to clear these when turned on her side. Respiratory obstruction recurred several times in the next 30 minutes, but was easily cleared using gauze wipes on a finger. That her reflexes were present was indicated by this finger being severely bitten during ane of these episodes! The hazardous situation was not helped by the nurse who was with the child during the induction period disappearing owing to a misunderstanding.

As Lieutenant-Colonel T. R. Austin and Captain D. R. Bevan point out, the induction of anaesthesia with ketamine is so easy that inexperienced anaesthetists may be tempted to use it. Both the preparation of the patient for, and the conduct of, the anaesthesia must be scrupulously carried out, and in the light of the above experience the premedication should include atropine, a drug which can often be dispensed with when using modern anaesthetics such as halothane. Whether the laryngeal reflexes are lost as Drs. P. A. Taylor and R. M. Tovey suggest, or retained as evidence from this hospital might suppose, ${ }^{1}$ pharyngeal reflexes are not adequate to deal with excessive secretions, blood, or presumably vomit.

It would be a shame if this drug which may have a tremendous potential in disaster or military situations should gain a reputation as a killer through careless usage, as thiopentone (Pentothal) did after Pearl Harbour. ${ }^{2-I}$ am, etc.,

\section{J. P. AlEXANDER}

Belfast City Hospital

Belfast

Moore, J. A., unpublished data.
Halford, F. J., Anesthesiology, 1943, 4, 67.

SIR,-The report by Lieutenant-Colonel T. R. Austin and Captain D. R. Bevan (19 June, p. 709) is a timely warning on the problems associated with ketamine in the presence of blood in the upper airway. I am in full agreement that the use of ketamine, despite its ease of administration, must be restricted to physicians skilled in the management of airway problems. While I appreciate that the patient these authors described was in no danger, the presence of blood or secretions in the upper airway can not only result in coughing but can also induce laryngeal spasm. In a series of now over 50 patients anaesthetized with ketamine for cardiac catheterization ${ }^{1}$ two patients developed laryngeal spasm as a result of secretions. The introduction of oxygen and halothane, combined with suction and further atropine, enabled this complication to be overcome. Withdrawal of halothane was accomplished without any recurrence.

The presence of blood and secretions in the upper airway would seem to be a contraindication to the use of ketamine as a sole agent. Careful selection of patients combined with the routine administration of atropine can increase the safety of this very useful anaesthetic agent.-I am, etc.,

Roval Victoria Hospital,

D. L. COPPEL

Belfast

Conpel, D. L., and Dundee, J. W., Anaesthesia (in press).

\section{Fractured Femur and Fat Embolism}

SIR,-The article by Dr. G. A. Gresham and others (12 June, p. 617) is the latest in a series of communications emphasizing the risks which are ascociated with the use of acrylic bone cement. The risk of fatal fat embolism is greatest in the elderly patient who has just sustained a fracture, but the way to avoid it is not to go back to nailing the subcapital fracture, a procedure which commonly ends in disaster, but to use an uncemented prosthesis. A simple Moore's replacement in these patients, performed at a reasonable technical level, can be expected to give a high standard of hip function with a low morbidity and mortality, and in most patients is the procedure of choice.

I would accept that fatal fat embolism is a very rare complication of a cemented total joint replacement, but this risk and the increased risk of infection, together with the doubts we must still have about its longterm stability, should lead us to evaluate whether the use of cement is necessary in each individual patient. A stable unipolar or bioolar replacement can be achieved in primary procedures without difficulty; in revisional surgery on the other hand, cement may be necessary in some patients on the 
femoral side. Loosening of an uncemented prosthesis is occasionally demonstrable on the radiographs, but is rarely associated with pain, and the incidence of loosening is certainly not greater in patients with osteoporosis than those with a normal bone structure. Under these circumstances, it seems unreasonable to expose patients to the additional hazards of bone cement, particularly after a femoral fracture, when an uncemented technique can be expected to give an equally satisfactory result.-I am, etc.,

Reigate, Surrey

P. A. RING

SIR,-I was most interested to read the report from Dr. G. A. Gresham and others (12 June, p. 617) concerning fat embolism following replacement arthroplasty for transcervical fractures of the femur.

I have now had three patients with fat embolism occurring after total knee replacement, one of whom died, and one occurring after a McKee arthroplasty. The one common feature in all these patients was that they were suffering from rheumatoid arthritis. In these patients the marrow fat is very excessive and almost liquid in consistency. It may well be that the rheumatoid patient is more liable to fat embolism following the insertion of acrylic cement.

Whatever the mechanism I feel certain that all surgeons who are using this material should be aware of the possibility of this complication. The diagnosis I am sure is often missed because the signs are masked when the patient is having a general anaesthetic. - I am, etc,

London W.1

N. H. HARRIS

\section{Accidental Poisoning with Malathion}

SIR,-A three-year-old girl was admitted with a history of having swallowed malathion, an organophosphorous insecticide. The patient presented with unconsciousness, cyanosis, constricted pupils, and excessive salivation. Thoracic respiratory movement was diminished and the rate of abdominal respiration was 28 per minute, the pulse was 130 , and the blood pressure was $80 / 60$.

Initial treatment was intubation with positive pressure oxygen and stomach aspiration. Atropine was given in doses of $0.03 \mathrm{mg}$ subcutaneously at ten-minute intervals on seven occasions. On this treatment the patient improved within one hour, by which time the colour was pink, the chest was moving normally at the rate of 16 per minute, the pupils were dilated, and the excessive salivation had dried up. However, two hours after her apparent recovery there was a complete relapse; there was again cyanosis, respiratory distress, constricted pupils, and salivation. This time oxygen was delivered with a "Venti-mask" and atropine $0.03 \mathrm{mg}$ was given on six occasions at ten-minute intervals. The patient responded well.

The next morning the patient had a light breakfast and was up playing with other children in the ward. The only abnormal clinical finding was a few scattered sibilant rhonchi in the left lung. Later on the same day the patient suffered repeated petit mal attacks tending to fall to one side. The attacks passed off without anticonvulsant therapy. The patient did not suffer any other ill effects and progressed uneventfully. Chest $x$-ray was normal as was the blood picture and she was discharged after five days' observation.

Malathion, dimethylphosphorothiolothionate, is the least toxic of the organophosphate insecticides and is used extensively in agriculture and in the veterinary field. The insecticide is approved by the U.K. Ministry of Agriculture, Fisheries, and Food, under the following names: Malathexo Dust, Malathion 60 Cyanamid, Malastan 60, Malathexo 60, Murphy Malathion 60, and Vitax Malathion 60 . Few cases of malathion poisoning in young children have been reported. ${ }^{1-3}$ The recommended dose of atropine in children should be $1 \mathrm{mg}$ to $2 \mathrm{mg}$ intravenously or intramuscularly every ten to fifteen minutes until the signs of atropinization appear and also that cholinesterase activators should be avoided. ${ }^{4}$ However, the value of pralidoxime chloride (Protopam) was advocated for treating the muscarinic effects $^{5} 6$ and also that treatment with pralidixime is effective only during the first day or two provided that absorption of the in secticide is complete. ${ }^{6}$ A report was made of respiratory paralysis due to acute necrotic myelitis following inhalation of fumes four days previously. ${ }^{7}$

It is hoped that this case will refresh memories on the treatment of organophosphate insecticide poisoning. - I am, etc.,

\section{F. H. EKIN}

Dr. Steeven
Dublin 8

$$
\begin{aligned}
& \text { Goldman. H., and Teitel, M., Fournal of Pedi- } \\
& \begin{array}{l}
\text { Goldman, H., and } \\
\text { atrics, 1958, 52, } 76
\end{array} \\
& \begin{array}{l}
\text { atrics, 1958, 52, } 76 . \\
\text { Tuthill, J. W. G., New England Fournal of Medi- }
\end{array} \\
& \text { cine, 1968. 258. } 1018 \\
& \text { Wenzl, J. E. and Burke, E. C. Fournal of the } \\
& \begin{array}{l}
\text { American Medical Association, 1962, 182. 495 } \\
\text { Silverio, J., Fournal of School Health, 1969, 39, }
\end{array} \\
& 607 . \\
& \begin{array}{l}
\text { Amos, W. C., and Hall, A., Annals of Internal } \\
\text { Mearcine. 1965, 62. 1013. }
\end{array} \\
& \text { Gitelson, S., Aladjemoff, L., Ben-Hador, S., and } \\
& \text { Katznelson, R. J., fournal of the American }
\end{aligned}
$$

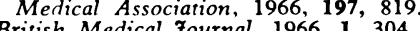

\section{Penicillin and the Mouth Flora}

SIR,-I beg your readers not to be misled by the claim of Professor O. Khairat (12 June, p. 650) that an intravenous dose of $275 \mathrm{mg}$ pyrrolidinomethyl tetracycline will abolish the bacteriaemia following dental extraction. I have refuted this claim in two other journals, ${ }^{1} 2$ but since he has repeated it in yours I must ask to be allowed to do so again. He persists in ignoring the fact that the very high immediate blood concentration achieved invalidates the results of his blood cultures. Taking this concentration as $24 \mu \mathrm{g}$ $\mathrm{ml}$, his broth cultures and pour plates must have contained 8 and $1.6 \mu \mathrm{g} / \mathrm{ml}$ respectively, and even the lower of these concentrations is more than enough to inhibit the growth of most mouth bacteria. This level remains constant in a culture, whereas that in the body falls as the antibiotic is excreted. In fact the "sterility" of these cultures is only apparent

There is no such thing as an antibacterial drug which will kill bacteria in the circulation within one minute. Penicillin and other appropriate bactericidal antibiotics require several hours. Tetracyclines, the action of which is little more than bacteristatic, can not be expected to do so at all.-I am, etc.

\section{Radlett,}

LAWRENCE P. GARRoD

\footnotetext{
1 Garrod, L. P., Lancet, 1967, 1. 795, 1275 .
2 Garrod, L. P., Fournal of Clinical Pathology
1967, 20, 304.
}

Management of Malignant Disease

SIR,-The report of the M.R.C. Working Party (22 May, p. 421) makes two points: (1) cytotoxic drugs as used by the method described has not increased survival of lung cancer, and (2) it may possibly have shortened the survival.

Those people practising the management of malignant disease and who have much experience in its control now feel unquestionably that it is vital that the immunological state should not be disturbed any more than is essential. As a result of 2,000 tests done at this hospital on the study of immune response certain conclusions have already been published.1 " These suggest that a good deal of immunological damage is done by cytotoxic drug treatment as in the manner employed in the trial, and it is not the slightest bit surprising that the results have been so bad. Conversely to general cytotoxic damage restriction of radiation to a precise zone of neoplastic invasion with the avoidance of radiation of normal tissue has resulted in a better response and it appears that metastases are now infrequently seen.

However, one swallow does not make a summer and a trial will be necessary to prove this. - I am, etc.,

Radiotherapy Department,

ANTHONy GreEN Royal Northern Hospital,

London $\mathrm{N}$.7

Green, A., British Medical fournal, 1969, 4, 622.

Green, A., British Medical fournal, 1971, 1, 173.

Dermatoglyphics and Chromosomes in Cateye Syndrome

SIR,-We have recently seen a $2 \frac{1}{2}$-year-old girl with features of the cat-eye syndrome: iris collobomata, preauricular fistulae, and anal atresia, as first described by Haab in $1878^{1}$ and clearly definable as a syndrome with the discovery of its chromosome anomaly by Schachenmann et al. in $1965 .^{2}$ Renal abnormalities have also been previously found in this syndrome, although no pathological changes have yet been demonstrated on intravenous pyelography in the present child. However, recurrent urinary infections have occurred.

In this patient, as in previously published cases, ${ }^{2-5}$ there is an extra chromosome, about half the size of those in group G. Morphologically the anomalous chromosome, in our patient, is submetacentric with satellites on the longer arm. Fifty metaphases examined in blood culture all had the extra marker chromosome.

The patient's father has a normal karyotype, but the mother was found to have the same marker chromosome in fifty metaphases studied in a blood culture. Since the mother lacked signs of cat-eye syndrome it is possible that she is in fact a mosaic in other tissues, as was actually found in another study. ${ }^{2}$ Similarly a previously reported example of the syndrome itself, reported to have a normal karyotype, ${ }^{9}$ may possibly have been an undetected mosaic.

Chromosomal anomalies occurring before the 13th week of fetal growth (when dermal patterns are being formed ${ }^{6}$ ) can be expressed phenotypically by abnormal dermatoglyphics, as we found in our patient.

Palm prints showed an unusually distal t (axial) triradius and an ulnar loop in the proximal hypothenar area on both palms. 